\title{
For the Benefit of Others: Reasons Why Women with Breast Cancer Participate in RCTs
}

\author{
Valerie A. Jenkins Lesley J. Fallowfield \\ Sussex Health Outcomes Research and Education in Cancer (SHORE-C), Brighton \& Sussex Medical School, University of Sussex, \\ Brighton, UK
}

\section{Keywords}

Breast cancer · Randomised clinical trials .

Patients' reasons

\section{Summary}

Background: Appreciation of the barriers and drivers affecting enrolment in randomised clinical trials (RCTs) is important for future trial design, communication and information provision. Methods: As part of an intervention to facilitate UK multidisciplinary team communication about RCTs, women with breast cancer who discussed trials with doctors or research nurses completed questionnaires examining i) clarity of trial information and ii) reasons for their trial decision. Results: 152 women completed the questionnaires; 113/152 (74\%) consented to RCT enrolment. Patients' satisfaction with communication about the trial information was very good, irrespective of participation decisions. Acceptors' and decliners' responses to 9/16 statements concerning decisions about trial participation differed significantly. 'Wanting to help with doctor's research' influenced 100\% acceptors compared to $57 \%$ of decliners $(p<0.001)$. Decliners were more likely to be 'worried about randomisation' (20 vs. $39 \% ; p<0.035)$ and to 'want doctor to choose treatment rather than be randomised' (31 vs. $53 \% ; p<0.031)$. Primary reason for trial acceptance was altruism; 'I feel that others with my illness will benefit from the results of the trial', 58/108 (54\%). Conclusion: A majority of women accepted RCT entry citing altruistic motivations as the primary driver for participation. Trial design and setting (metastatic or adjuvant) had little impact on participation.

\section{Introduction}

Appreciation of the barriers and drivers affecting enrolment in randomised clinical trials (RCTs) is important. A lack of awareness of the factors influencing participation can lead to overly optimistic predictions of likely enrolment numbers and slow recruitment. Not all patients join RCTs; understanding some of the reasons for rejecting participation is useful to inform future information, communication needs and trial design.

Patients' attitudes towards trials are generally positive, but the concept of randomisation is a difficult one for many to comprehend [1-3]. Randomisation emerged as a major barrier in 1 study, with women more likely than men to be dissuaded from trial entry when randomisation was introduced [4]. Also cultural differences are found, for example a US study reported that African American women with breast cancer had significantly more negative attitudes towards RCTs than others, which furthermore were not altered by an interventional explanatory video [5]. However, a survey that examined racial/ethnic factors in trial involvement noted that the length of the patient information pamphlet ( $\geq 20$ pages) was significantly associated with a lower odds of 'no desire to participate' rather than ethnicity [6].

Age can be another barrier to trial recruitment. A review of studies examining barriers to participation in breast cancer trials for older women showed that potential toxicities and comorbidityrelated questions represented the main obstacles for clinicians, whereas randomisation was more of concern to patients [7].

Throughout the course of treatment there are many opportunities for women with breast cancer to engage in clinical trials, for example in the perioperative period, the adjuvant setting, and/or the metastatic setting. Some may question the ethics of engaging patients in more than 1 trial, but many would consider entering more than 1 study and believe there should not be a limit on the number offered [8]. 
Although trials may address pertinent scientific questions, not all trial designs are equally attractive to patients. 1 study of 204 patients, 112 of whom were women with breast cancer, showed a significantly higher acceptance rate for trials providing active treatment in every arm (81\%) compared with trials with a notreatment arm (61\%) [9]. Often trials have multiple treatment arms, and this complexity of randomisation to 4 or more different treatment groups can be quite overwhelming. In the case of breast cancer, a growing number of trials are perioperative, and require extra tumour samples or additional imaging that may delay surgery. Other trial designs might offer a novel treatment compared with standard therapy, or a longer duration of standard treatment, which some patients may assume must be better. While the scientific community regards trials with placebo control and a no-treatment arm as the scientifically purest design for testing the efficacy of new therapies, they may be least favoured by patients who in the face of potentially life-threatening disease want an overtly active treatment. Interestingly, a survey of $>115,000 \mathrm{can}-$ cer patients in the USA reported that those with poor prognosis tumours (e.g. ovarian) and those with advanced disease (e.g. metastatic breast cancer) were most likely to request study information about trials compared with those contemplating adjuvant treatments [10].

The results presented in this paper examine the barriers and drivers affecting recruitment to breast cancer trials in UK women. The data were gathered as part of a larger Cancer Research UK (CRUK)-funded prospective study that examined multidisciplinary team members' communication about RCTs [11].

\section{Materials and Methods}

Patients who had discussed a trial with a doctor and/or research nurse from any of the 24 multidisciplinary teams participating in the CRUK study were given 2 study-specific questionnaires to complete at home and return by post to the coordinating centre. Each team was asked to provide monthly information regarding the number of patients who were given the questionnaires, together with their age and sex. The study had multicentre ethical approval (South East Wales Local Research Ethics Committee Ref: 07/WSE03/17) and local NHS $\mathrm{R} \& \mathrm{D}$ permissions. This paper deals with only the responses from the women with breast cancer. The questionnaires probed the following.

Reasons for Accepting or Declining Trial Entry \& Main Reason for Choice

This study-specific 16-item questionnaire was modified from Penman et al. [12] and used in previous research of phase III trials [13]. The questionnaire comprises an initial question establishing whether or not the patient has agreed to trial entry. For each of the 16 statements, patients registered their agreement or disagreement on a scale of $0-4$ ( 0 , strongly agree; 1 , agree to some extent; 2 , unsure; 3 , disagree to some extent; and 4, strongly disagree). Finally patients indicated from the options available the most important reason for their decision.

\section{Clarity of Communication}

This 15-item questionnaire was used to rate the clarity of the trial information provided by the team member. First patients indicated who had spoken with them about the trial (e.g. research nurse or clinician), and where possible the name of the trial. Thereafter patients rated their agreement with statements using a scale of $0-4$ ( 0 , not at all clear; 1 , a little bit clear; 2 , somewhat clear; 3 ,
Table 1. Characteristics of participants $(n=152)$

$\mathrm{n}(\%)$

\begin{tabular}{lc}
\hline Age group, years & \\
$29-50$ & $28(21)$ \\
$51-69$ & $84(65)$ \\
$70+$ & $18(14)$ \\
Missing & 21 \\
Treatment aim & $110(79)$ \\
$\quad$ Primary & $30(21)$ \\
Further for advanced disease & 12 \\
Missing & \\
Trial type & $45(33)$ \\
Placebo controlled & $67(49)$ \\
Standard (Std) vs. Std given at different & \\
$\quad$ duration or different therapy & $25(18)$ \\
Std vs. Std +/- new agent & 15 \\
Missing & \\
Take part in trial & $113(74)$ \\
Yes & $31(20)$ \\
No & $8(5)$ \\
Don't know &
\end{tabular}

quite a bit clear; and 4, very clear). These statements included clarity about explanations of randomisation and side effects of treatments. It has been used in a previous communication study with simulated patients [14].

\section{Statistical Analyses}

Summary statistics were generated for the descriptive data: counts, percentages and averages. Chi-square tests with continuity corrections as appropriate were conducted on comparison data between acceptors and decliners of trials. Type of trial was categorised by entering the name of the trial from the patient questionnaires into the National Cancer Research Network and CRUK trial databases. We devised 3 trial categories; placebo control, standard vs. new therapy/regimen, standard therapy $+/$ - new agent. Trial type also allowed us to categorise the patients as receiving treatment for adjuvant or advanced disease. Previous trial experience was unknown.

\section{Results}

Cancer teams recruited 152 women with breast cancer to the communication study over a period of 3 years. Participants were aged between 29 and 87 years (table 1); the majority (65\%) were in the age group 51-69 years.

Most women indicated that the trial information was provided more often by the research nurse $(111 / 146 ; 76 \%)$ than by the doctor $(28 / 146 ; 19 \%)$, although a few reported both $(7 ; 5 \%)$, reflecting UK practice. The majority of women $(113 / 152 ; 74 \%)$ agreed to participate in a trial, 31/152 (20\%) declined, and $8(5 \%)$ were unsure if they were in a trial or not. Most of the trials offered were in the adjuvant setting $(110 / 140 ; 79 \%)$, rather than for treatment of advanced or metastatic disease $(30 / 140 ; 21 \%)$. Table 2 shows acceptance rate by trial type with an example of a trial for each category. There was no significant difference in acceptance rates by trial design $\left(\mathrm{chi}^{2}=8.066, \mathrm{df}=1, \mathrm{p}=0.89\right)$ but a smaller proportion $(64 \%)$ of those offered standard $+/$ - a new treatment agreed to trial par- 
Table 2. Example of breast trials, type and overall acceptance rates
Table 3. Table showing proportion of participants agreeing to each statement divided into those who accepted or declined trial entry (don't knows were excluded) $\left(\mathrm{x}^{2}\right.$, Fisher's exact)

\begin{tabular}{|c|c|c|}
\hline Trial design & Acceptance, n (\%) & Examples of trials within that design \\
\hline $\begin{array}{l}\text { Standard therapy versus } \\
\text { standard }+/ \text { - novel drug }\end{array}$ & $16 / 25(64)$ & $\begin{array}{l}\text { OPTION - chemotherapy }+/ \text { - goserelin } \\
\text { SUPREMO - mastectomy }+/ \text { - radiotherapy to the chest wall }\end{array}$ \\
\hline $\begin{array}{l}\text { Standard versus new therapy } \\
\text { or regimen }\end{array}$ & $54 / 67(81)$ & $\begin{array}{l}\text { AMAROS - axillary radiotherapy vs. axillary lymph node dissection } \\
\text { PERSEPHONE - } 12 \text { vs. } 6 \text { months trastuzumab }\end{array}$ \\
\hline Placebo control & $33 / 45(73)$ & REACT - double blind randomized controlled trial celecoxib vs. placebo \\
\hline
\end{tabular}

\begin{tabular}{|c|c|c|c|}
\hline Statement & $\begin{array}{l}\text { Accept } \\
(\mathrm{n}=113), \mathrm{n}(\%)\end{array}$ & $\begin{array}{l}\text { Decline } \\
(\mathrm{n}=31), \mathrm{n}(\%)\end{array}$ & $\mathrm{p}$ value \\
\hline 1. I thought the trial offered the best treatment available & $\begin{array}{l}90 / 108^{* * * *} \\
(83)\end{array}$ & $\begin{array}{l}10 / 31 \\
(32)\end{array}$ & $<0.001$ \\
\hline 2. I believed the benefits of treatment in the trial would outweigh the side effects & $\begin{array}{l}98 / 111^{\star *} \\
(88)\end{array}$ & $\begin{array}{l}12 / 31 \\
(39)\end{array}$ & $<0.001$ \\
\hline 3. I was satisfied that either treatment in the trial would be suitable & $\begin{array}{l}102 / 111^{* *} \\
(92)\end{array}$ & $\begin{array}{l}14 / 31 \\
(45)\end{array}$ & $<0.001$ \\
\hline 4. I was worried that my illness would get worse unless I joined the trial & $\begin{array}{l}12 / 108^{* * * *} \\
(11)\end{array}$ & $\begin{array}{l}2 / 31 \\
(7)\end{array}$ & 0.735 \\
\hline 5. The idea of randomization worried me & $\begin{array}{l}22 / 111^{\star *} \\
(20)\end{array}$ & $\begin{array}{l}12 / 31 \\
(39)\end{array}$ & 0.035 \\
\hline $\begin{array}{l}\text { 6. I wanted a doctor to choose my treatment rather than be randomised by } \\
\text { computer }\end{array}$ & $\begin{array}{l}34 / 111^{\star *} \\
(31)\end{array}$ & $\begin{array}{l}16 / 30^{*} \\
(53)\end{array}$ & 0.031 \\
\hline 7. The doctor told me what I needed to know about the trial & $\begin{array}{l}107 / 111^{* *} \\
(96)\end{array}$ & $\begin{array}{l}30 / 31 \\
(97)\end{array}$ & 1.00 \\
\hline 8. I trusted the doctor treating me & $\begin{array}{l}111 / 111^{\star *} \\
(100)\end{array}$ & $\begin{array}{l}30 / 30^{*} \\
(100)\end{array}$ & - \\
\hline 9. I was given too much information to read about the trial & $\begin{array}{l}9 / 108^{* * * *} \\
(8)\end{array}$ & $\begin{array}{l}1 / 30^{*} \\
(3)\end{array}$ & 0.69 \\
\hline 10. I was given enough information to read about the trial & $\begin{array}{l}109 / 112^{*} \\
(97)\end{array}$ & $\begin{array}{l}30 / 31 \\
(97)\end{array}$ & 1.00 \\
\hline 11. I knew I could leave the trial at any time and still be treated & $\begin{array}{l}111 / 111^{* *} \\
(100)\end{array}$ & $\begin{array}{l}29 / 31 \\
(94)\end{array}$ & $0.046^{\mathrm{a}}$ \\
\hline 12. I did not feel able to say no & $\begin{array}{l}7 / 110^{* * *} \\
(6)\end{array}$ & $\begin{array}{l}0 / 31 \\
(0)\end{array}$ & 0.347 \\
\hline 13. I wanted to help with the doctor's research & $\begin{array}{l}112 / 112^{*} \\
(100)\end{array}$ & $\begin{array}{l}17 / 30^{*} \\
(57)\end{array}$ & $<0.001$ \\
\hline 14. I feel that others with my illness will benefit from the results of trial & $\begin{array}{l}111 / 111^{* *} \\
(100)\end{array}$ & $\begin{array}{l}29 / 31 \\
(94)\end{array}$ & $0.046^{\mathrm{a}}$ \\
\hline 15. The doctor wanted me to join the trial & $\begin{array}{l}44 / 107^{\star * * * *} \\
(41)\end{array}$ & $\begin{array}{l}12 / 30^{*} \\
(40)\end{array}$ & 1.00 \\
\hline 16. Others, for example, family or friends, wanted me to join the trial & $\begin{array}{l}60 / 108^{* * * *} \\
(56)\end{array}$ & $\begin{array}{l}3 / 30^{*} \\
(10)\end{array}$ & $<0.001$ \\
\hline
\end{tabular}

${ }^{\mathrm{a} C}$ Caution is required when interpreting significance due to multiple analyses.

${ }^{*} 1$ response missing.

$* * 2$ responses missing.

$* * * 3$ responses missing.

$* * * * 5$ responses missing.

$* * * * \star 6$ responses missing. 
Table 4. Table showing proportion of participants who either accepted or declined trial entry, agreeing to each statement about the clarity of trial communication $\left(\mathrm{x}^{2}\right.$, Fisher's exact $)$

\begin{tabular}{|c|c|c|c|}
\hline Statement & $\begin{array}{l}\text { Accept } \\
(\mathrm{n}=113) \\
\mathrm{n}(\%)\end{array}$ & $\begin{array}{l}\text { Decline } \\
(\mathrm{n}=31), \\
\mathrm{n}(\%)\end{array}$ & $\begin{array}{l}\mathrm{p} \\
\text { value }\end{array}$ \\
\hline $\begin{array}{l}\text { 1. The healthcare professional (HCP) used clear and under- } \\
\text { standable language }\end{array}$ & $\begin{array}{l}113^{*} \\
(100)\end{array}$ & $\begin{array}{l}31 \\
(100)\end{array}$ & \\
\hline 2. I understood that entry into the trial was voluntary & $\begin{array}{l}113 \\
(100)\end{array}$ & $\begin{array}{l}31 \\
(100)\end{array}$ & - \\
\hline $\begin{array}{l}\text { 3. I understood if I agreed to join the trial I could leave at any } \\
\text { time }\end{array}$ & $\begin{array}{l}113 \\
(100)\end{array}$ & $\begin{array}{l}29 \\
(93)\end{array}$ & 0.045 \\
\hline 4. I understood the HCP's explanation of randomisation & $\begin{array}{l}113 \\
(100)\end{array}$ & $\begin{array}{l}31 \\
(100)\end{array}$ & - \\
\hline 5. I felt the HCP was sensitive to my concerns & $\begin{array}{l}113 \\
(100)\end{array}$ & $\begin{array}{l}31 \\
(100)\end{array}$ & - \\
\hline 6. I was given the opportunity to ask questions & $\begin{array}{l}112 / 113 \\
(99)\end{array}$ & $\begin{array}{l}31 \\
(100)\end{array}$ & 1.00 \\
\hline 7. I was left confused & 0 & 0 & - \\
\hline 8. I felt the HCP listened to what I had to say & $\begin{array}{l}111 / 111^{* *} \\
(100)\end{array}$ & $\begin{array}{l}31 \\
(100)\end{array}$ & - \\
\hline 9. I understood the treatment options available outside the trial & $\begin{array}{l}106 / 110^{* * *} \\
(96)\end{array}$ & $\begin{array}{l}28 \\
(90)\end{array}$ & 0.179 \\
\hline $\begin{array}{l}\text { 10. I was informed about possible side effects of the different } \\
\text { treatments }\end{array}$ & $\begin{array}{l}105 / 110^{* * *} \\
(95)\end{array}$ & $\begin{array}{l}27 \\
(87)\end{array}$ & 0.107 \\
\hline 11. The HCP seemed to favour one treatment over another & $\begin{array}{l}4 / 106^{* * * *} \\
(4)\end{array}$ & $\begin{array}{l}1 \\
(3)\end{array}$ & 1.00 \\
\hline $\begin{array}{l}\text { 12. I felt that } \mathrm{HCP} \text { gave me all the information I needed to } \\
\text { make decision }\end{array}$ & $\begin{array}{l}111 \\
(100)\end{array}$ & $\begin{array}{l}31 \\
(100)\end{array}$ & - \\
\hline $\begin{array}{l}\text { 13. I felt that the HCP created an atmosphere of trust and } \\
\text { support }\end{array}$ & $\begin{array}{l}110 / 111 \\
(99)\end{array}$ & $\begin{array}{l}31 \\
(100)\end{array}$ & 1.00 \\
\hline $\begin{array}{l}\text { 14. I felt that the } \mathrm{HCP} \text { gave me time to consider entry into the } \\
\text { trial }\end{array}$ & $\begin{array}{l}111 \\
(100)\end{array}$ & $\begin{array}{l}31 \\
(100)\end{array}$ & - \\
\hline 15. I still have unanswered questions & $\begin{array}{l}2 / 107^{* * * *} \\
(2)\end{array}$ & $\begin{array}{l}2 \\
(7)\end{array}$ & 0.199 \\
\hline $\begin{array}{l}{ }^{*} 1 \text { missing response. } \\
{ }_{* \star} 2 \text { missing responses. } \\
{ }_{* * *} \text { missing responses. } \\
{ }_{* * * *} 4 \text { or more missing responses. }\end{array}$ & & & \\
\hline
\end{tabular}

'I feel that others with my illness will benefit from the results of the trial' (58/108; 54\%), and 'trust in the doctor' for those who declined a trial $(7 / 31 ; 23 \%)$. Although altruism was selected as the main reason for joining a trial, the free text comments show that it was interwoven with wanting to also help themselves, as these quotes illustrate:

'I am happy to take part in any trial that may benefit not only me, but others who may need to have treatment for cancer', ID 08.

'I am very pleased to be asked to take part in these trials as I think they will be beneficial to myself e.g. having extra scans, blood tests etc. and to help other people with my illness on the outcome of the trials', ID 66.

Patients' satisfaction with communication about trial information was very good, irrespective of participation decision, or trial type (table 4 ).

\section{Discussion}

The majority of women returning questionnaires had decided to participate in a randomised clinical trial as part of their treatment plan. Those who declined trial entry were more likely to be worried about randomisation, felt less strongly about helping with the doctor's research, and did not agree as strongly that the benefits of treatment would outweigh the side effects. Importantly women who declined were as satisfied with the information received and the clarity of it as those who agreed to participate.

Previously we reported a significantly higher acceptance rate for trials with an active treatment arm compared with trials that had a no-treatment or placebo group [9]; however this included patients with all solid common tumours. The current analysis focused only on women with breast cancer, and although there were no significant differences in acceptance rates between trial types, numerically fewer women accepted trials that offered standard therapy $+/$ a new treatment as a primary therapy following breast cancer sur- 
gery. The trials in question were radiotherapy to the chest wall and axilla following mastectomy, and ovarian protection for premenopausal women having chemotherapy.

Irrespective of the trial decision all patients indicated that they trusted the doctor treating them, and this was the main reason given by decliners, suggesting that these doctors had provided a very even handed explanation of the trial and stressed the voluntary nature of participation convincingly. Women who had accepted trial participation stated that they wanted to help others in the future, but also believed the trial offered them the best treatment, which perhaps allowed them to feel more altruistic. While it is possible that many patients with cancer are genuinely selfless, it must be highlighted that social desirability may influence endorsement of altruistic statements if these are provided as options on a questionnaire. The authors of 1 study coined the term 'conditional altruism' to describe the situation where people agree to randomisation as an opportunity to help others but hopefully themselves [15]. Of course patients who participate in questionnaire research may be more positively inclined to research in general, including clinical trials, which may have given us a bias sample, in that those who did not return questionnaires may also have declined trial entry.

In the UK many discussions with patients about breast cancer trials take place over time with various members of a cancer team, both formal and informal. This is of enormous benefit if team members are supportive and knowledgeable about the trial, but detrimental if unclear or have an antipathy toward the trial [16]. Virtually all new trials have sub-studies that may need extra tumour samples taken, more histopathology and additional imaging or other screening tests. This leads to greater patient burden, involving more hospital visits for tests, and involves complex information giving for the healthcare professionals [11]. Often the content and readability of trial recruitment resources is at too high a reading level [17], and health professionals overestimate their patients' health literacy skills [18]. In addition the fact that poor functional health literacy can imply problems in understanding oral communication is overlooked [19]. There have been various efforts to circumvent these problems such as employing educational interventions to improve healthcare professionals' general communication skills and their discussions about trials with patients and members of their own cancer team [14, 20,21]. Also required is information in a more accessible format that compliments the trial information sheets but enables patients to revisit sections easily. One such resource is patient information DVDs developed for specific cancer trials. We have produced several with input from patients, the lay public, and trial management committees. They are particularly useful when a trial is predicted to be one that may, because of the complexity of the design, heighten communication difficulties with patients. For example surgical trials have struggled or failed to recruit sufficient patient numbers due to the very different treatment arms on offer and a perception by patients, in the context of life-threatening disease, that 'doing something' or something more radical must surely be better than just 'waiting for something to happen'. The trial information DVDs are patient friendly, include graphics and simple illustrations of randomisation, the rationale of the trial, the difference between the groups, and other trial information. Some also include a session with the Chief Investigator of the study answering further questions from women contemplating the trial.

\section{Conclusion}

This small study did demonstrate that if approached most women with breast cancer are willing to participate in RCTs, irrespective of the treatment aim that is, in the adjuvant or advanced disease setting. Furthermore trial design did not appear to have a significant impact. Women with breast cancer in this sample were primarily motivated by altruism. As in other research randomisation seems to be the primary deterrent. Good educational aides as well as communication might assist in explaining the need, scientific logic for chance allocation and safety of the approach.

\section{Acknowledgement}

We wish to thank the patients, research and clinic nurses, and clinicians engaged in the study. Cancer Research UK funded the study; grant number C54/ A7374.

\section{Disclosure Statement}

The authors have no conflicts of interest to declare.

\section{References}

1 Fallowfield LJ, Jenkins V, Brennan C, Sawtell M, Moynihan C, Souhami RL: Attitudes of patients to randomised clinical trials of cancer therapy. Eur J Cancer 1998;34:1554-1559.

2 Ellis PM: Attitudes towards and participation in randomised clinical trials in oncology: a review of the literature. Ann Oncol 2000;11:939-945.

3 Catania C, De Pas T, Goldhirsch A, Radice D, Adamol L, Medici M, Verri E, Marenghi C, De Braud F, Nole F Participation in clinical trials as viewed by the patient: understanding choice and emotional aspects which influence choice. Oncology 2008;74:177-187.
4 Jenkins V, Farewell D, Batt L, Maughan T, Branston L, Langridge C, Parlour L, Farewell V, Fallowfield LJ: The attitudes of 1,066 patients with cancer towards participation in randomised clinical trials. Br J Cancer 2013; 103:1801-1807.

5 Du W, Mood D, Gadgeel S, Simon MS: An educational video to increase clinical trials enrollment among breast cancer patients. Breast Cancer Res Treat 2009; 117:339-347.
6 Langford AT, Resnicow K, Dimond EP, Denicoff AM Germain DS, McCaskill-Stevens W, Enos RA, Carrigan A, Wilkinson K, Go RS: Racial/ethnic differences in clinical trial enrollment, refusal rates, ineligibility, and reasons for decline among patients at sites in the $\mathrm{Na}$ tional Cancer Institute's Community Cancer Centers Program. Cancer 2014;120:877-884.

7 Townsley CA, Selby R, Siu LL: Systematic review of barriers to the recruitment of older patients with cancer onto clinical trials. J Clin Oncol 2005;23:3112-3124. 
8 Burnet K, Earl H, Thornton H, Cox K, Purushotham AD: A survey of breast cancer patients' views on entry into several clinical studies. Eur J Cancer Care (Engl) 2004;13:32-35.

9 Jenkins V, Fallowfield L: Reasons for accepting or declining to participate in randomised clinical trials for cancer therapy. Br J Cancer 2001;82:1783-1788.

10 Markman M, Petersen J, Montgomery R: Influence of tumour type, disease status and patient age on self-reported interest regarding participation in cancer clinical trials. Cancer 2006;107:849-853.

11 Jenkins V, Farewell D, Farewell V, Batt L, Wagstaff J, Langridge C, Fallowfield LJ; Teams Talking Trials Steering Committee: Teams Talking Trials: results of an RCT to improve the communication of cancer teams about treatment trials. Contemp Clin Trials 2013; 35:43-51.
12 Penman DT, Holland JC, Bahna GF, Morrow G, Schmale AH, Derogatis LR, Carnrike CL Jr, Cherry R: Informed consent for investigational chemotherapy: patients' and physicians' perceptions. J Clin Oncol 1984;2:849-855.

13 Fleissig A, Jenkins V, Fallowfield L: Results of an intervention study to improve communication about randomised clinical trials of cancer therapy. Eur J Cancer 2001;37:322-331.

14 Jenkins V, Fallowfield LJ, Solis-Trapala I, Langridge C, Farewell V: Discussing randomised clinical trials of cancer therapy: evaluation of a Cancer Research UK training programme. BMJ 2005;330:400-403.

15 McCann SK, Campbell Mk, Entwistle VA, Smith D: Reasons for participating in randomised controlled trials: conditional altruism and considerations for self. Trials 2010;11:31.

16 Fallowfield L, Langridge C, Jenkins V: Communication skills training for breast cancer teams talking about trials. Breast 2014;23:193-197.
17 Paasche-Orlow MK, Taylor HA, Brancati FL: Readability standards for informed consent forms as compared with actual readability. N Engl J Med 2003;348:721726.

18 Dickens C, Lambert BL, Cromwell T, Piano MR: Nurse overestimation of patients' health literacy. J Health Comm 2013;18:62-69.

19 Friedman DB, Hoffman-Goetz L: A systematic review of readability and comprehension instruments used for print and web-based cancer information. Health Educ Behav 2006;33:352-373.

20 Fallowfield L, Jenkins V, Farewell V, Saul J, Duffy A, Eves R: Efficacy of a Cancer Research UK communication skills training model for oncologists: a randomized controlled trial. Lancet 2002;359:650-656.

21 Fallowfield LJ, Solis-Trapala I, Jenkins V: Evaluation of an educational program to improve communication with patients about early-phase trial participation. Oncologist 2012;17:377-383. 